\title{
Joint Inversion of Receiver Function and Dispersion of Rayleigh Waves for Determin- ing of Layer Velocity Models in the Chaco-Paraná Basin
}

\author{
Pedro L. A. Moraes¹, Marcelo S. Assumpção1; 1|AG-USP
}

Copyright 2021, SBGf - Sociedade Brasileira de Geofísica

This paper was prepared for presentation during the $17^{\text {th }}$ International Congress of the Brazilian Geophysical Society held in Rio de Janeiro, Brazil, 16-19 August 2021.

Contents of this paper were reviewed by the Technical Committee of the $17^{\text {th }}$ In ternational Congress of the Brazilian Geophysical Society and do not necessarily represent any position of the SBGf, its officers or members. Electronic reproduction or storage of any part of this paper for commercial purposes without the written consent of the Brazilian Geophysical Society is prohibited.

\section{Abstract}

Receiver functions and surface waves have been used to study crust and lithosphere under the Chaco-Paraná Basin during recent years. However the upper crust in the region still lacks information, given that these studies have focused on the deep structure of the crust and have not had resolution for shallow structure. We inverted high frequency receiver functions, as well as dispersion curves to obtain Vs-profiles, focusing on the shallow structure of the crust. We used a procedure of joint inversion of receiver function and dispersion curves to estimate the basement depth under six stations of the XC and BL networks. The results show the basement at about $2.0 \mathrm{~km}$ and the Moho interface at $40.3 \mathrm{~km}$. We had high uncertainty estimations for sedimentary layers due to the long periods used in dispersion, which was not able to retrieve the inversion in these layers. Despite that, we were able to identify two types of sedimentary layers, which we associate with an older and more compact sedimentation of higher $V s$ and a more recent and less compact sedimentation of lower Vs.

\section{Introduction}

Chaco-Paraná Basin (CPB) has been the target of recent studies (e.g. Rivadeneyra-Vera et al., 2019), since the sedimentary basins in the central portion of South America are some of the least studied areas in the continent. It covers North-Argentina, most of Paraguai and South of Brazil (Fig. 1).

The CPB was formed west of Gondwana, most of its surface is covered by recents quaternary deposits. The region has had several episodes of subsidence, its sedimentation began in Paleozoic and extended until the Cenozoic. The CPB shares some sequences with the Paraná Basin from Carboniferous to Cretaceous (Milani \& Thomaz Filho, 2000).

In 2019, Rivadeneyra-Vera et al. presented a crustal model of South America, adding data from new stations installed in the sedimentary basins of the central portion of the continent to the Assumpção et al. (2013) crustal mo- del. The results revealed that Moho is deeper than expected for the CPB, between 35 and $40 \mathrm{~km}$ deep.

Although the recent advances in the deep structure of the crust, the shallow structure still lacks information. Some work has been done in the area (e.g. Feng et al., 2007; Lloyd, et al., 2010; Chulick, et al., 2013), but as pointed by Rosa et al. (2016), they used data sets with no resolution for retrieving the inversion on the sedimentary and shallow layers. So, basement depth estimates lack more confirmation.

Receiver function (RF) is widely used in crustal studies to determine wave propagation velocity profiles (Ammon, 1991; Owens et al., 1984). Due to a non-unique inversion problem, it is common that RF is jointly inverted with surface waves dispersion curves (DC) (e.g., Julià et al., 2000). Joint inversion of high frequency RF and DC can be used to study shallow crustal structure (e.g. Assumpção et al., 2009). Rosa et al. (2016) estimated basement depth at about $5 \mathrm{~km}$ under $\mathrm{CPB}$, but with no resolution for a good retrieving. High frequency receiver functions could bring a more reliable estimate of the basement depth in the region.

In this work, we use receiver functions and dispersion curves to calculate S-wave velocity profiles beneath the Chaco-Paraná Basin, providing more data of the shallow structure of the crust in the region.

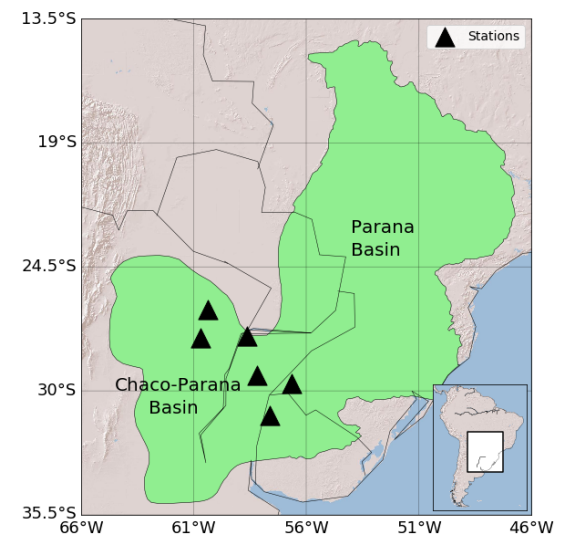

Fig. 1 - Chaco-Paraná Basin with stations in triangles.

\section{Methods}

Deconvolution of radial and vertical components of seismograms removes source and instrument effects and isolates the geological structure near the station site 


\title{
Joint Inversion of Receiver Function and Dispersion Curves of Rayleigh Waves for determining of
}

\author{
Layer Velocity Models in the Chaco-Paraná Basin
}

(Ammon et al., 1990). The resulting trace, the receiver function (RF), marks the arrival times of P-to-S conversions and the reverberations under the station (Fig. 2).

To calculate the RFs for the CPB, we selected events of distance $<30^{\circ}$ (to avoid attenuation of high frequencies in the asthenosphere) and depth $>400 \mathrm{~km}$ (for an approximately vertical incidence) recorded at six stations of XC and $\mathrm{BL}$ networks of CPB region (Fig. 1). We applied time domain deconvolution (Ligorría and Ammon, 1999) with gaussian filters of $0.25,0.5,1,2.5,4$ and $5 \mathrm{~Hz}$ (gaussian width parameter of $0.5,1,2,5,8$ and 10 , respectively).
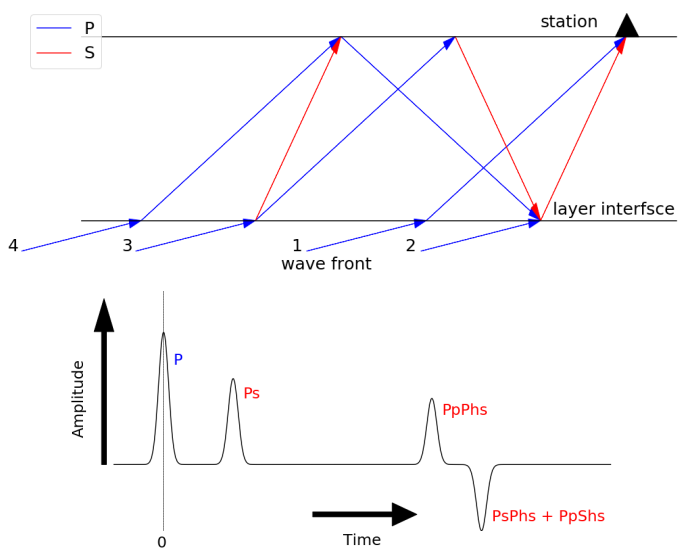

Fig 2 - Example of P-to-S conversions from a single layer (top) and a receiver function (bottom), with $P$ phase (1), $P s$ conversion (2) and multiples: PpSs + PsPs (3) and PpPs (4).

Three criteria were used to determine if a RF should be used or discarded. First, the RF should not have a negative first pulse, because it would imply that the first arrival had an inverted polarization in relation to itself, which has no geological meaning. So, these RF were attributed to noisy data. Second, the convolution of the RF with the vertical component should correspond to the radial in, at least, $85 \%$. Third, the main pulses of different RF's from the same station should arrive at the same time, approximately. This avoids the data to sample different geology under the station due to different arrival directions of the waves.

The RF inversion is a non-unique inversion problem, since each peak in the signal can be interpreted as a Ps conversion in an interface or as a reverberated multiple. The joint inversion of dispersion curves (DC) is a way to bring stability to the inversion (e.g. Julià et al., 2000; Assumpção et al., 2009). We used DC of phase and group velocity of Rayleigh waves from Shirzad et al. (2020) in the CPB region, with periods ranging from 6 to $80 \mathrm{~s}$.

We used the results of Rosa et al. (2016) to create initial models for joint inversion. In their work, they say that the basement depth and sedimentary layers are not well constrained, due to their data that did not have resolution for shallow layers. So, our initial model may be a good approximation for retrieving the depth of Moho and other deep layers. We also based the initial models on the results of Rivadeneyra-Vera et al. (2019), which are focused on deep structure. We used a $\mathrm{Vp} / \mathrm{Vs}$ factor of 1.8 for sedimentary layers and 1.73 for crystalline layers. For joint inversion we used Julià et al. (2000) program, which is a damped minimum square linearization with regularization. The regularization provides smoothness to the inversion, preventing the model from having layers with much different S-wave velocity from adjacent layers. But it also prevents the inversion from converging to a model with discontinuities where they really exist. So, the program allows the user to control how much each layer is affected by regularization. We used this feature to better restrict the discontinuities of Moho and the basement.

We did the proceeding several times for each station, changing the initial model by up to $10 \%$. So, we calculated a set of final models for each station, which gives us an estimate of the uncertainty.

\section{Results}

Here we present the results for six stations in the CPB, five of the XC network (MECA, PSAL, SCCA, TICA and VACA), located in Paraguay and Argentina, and one of the BL network (ITQB), located in Rio Grande do Sul state, Brazil. Fig. 3 shows that ITQB, MECA and PSAL stations are located on volcanic rocks of the Cretaceous, whereas the other stations are stalled on the sedimentary cover of the Quaternary.

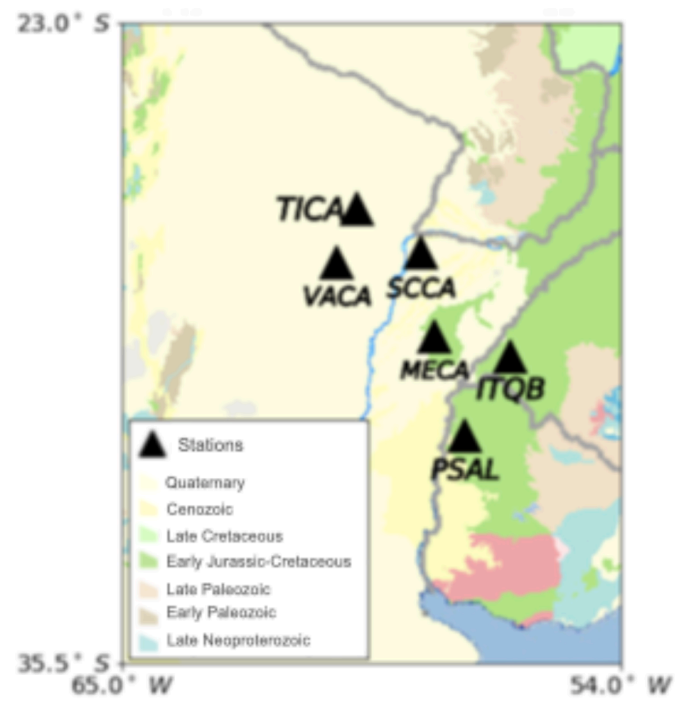

Fig 3- Geological map of the CPB region, showing the locations of the six stations.

Figs. 4 to 21 show the results of the inversion: the S-wave velocity models and the predicted data, calculated from these models, in comparison with the observed data. 
Pedro L. A. Moraes, Marcelo S. Assumpção

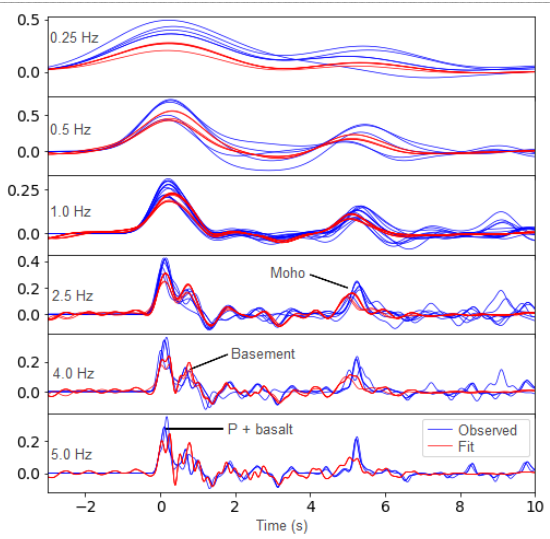

Fig. 4 - Inversion of receiver functions of frequencies 0.25 (top), $0.5,1,2.5,4$ and $5 \mathrm{~Hz}$ (bottom) of ITQB station.

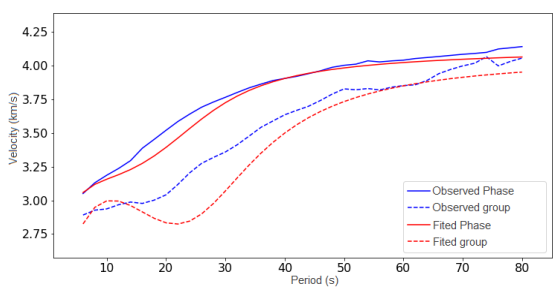

Fig. 5 - Inversion of dispersion curves of Rayleigh waves of ITQB station.

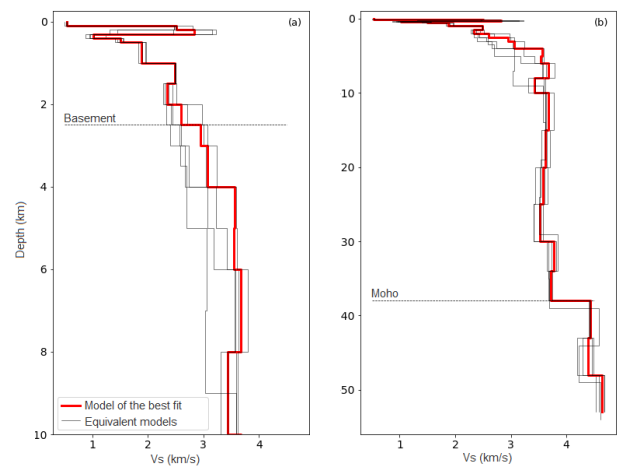

Fig. 6 - Final models of inversions for ITQB station. The profile on the left (a) shows the first $10 \mathrm{~km}$, the profile on the right (b) shows the entire velocity model.

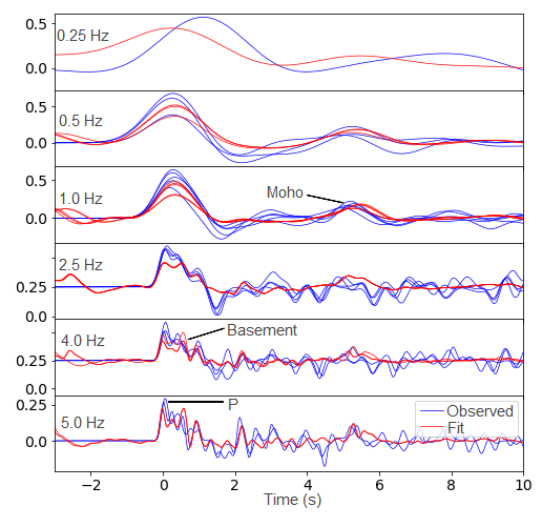

Fig. 7 - Inversion of receiver functions of frequencies 0.25 (top), $0.5,1,2.5,4$ and $5 \mathrm{~Hz}$ (bottom) of MECA station.

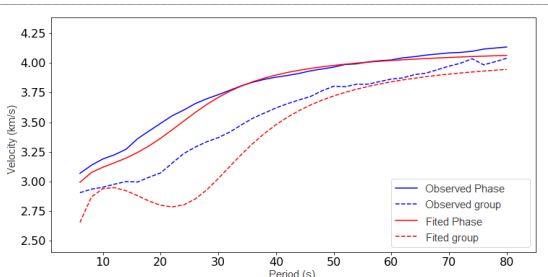

Fig. 8 - Inversion of dispersion curves of Rayleigh waves of MECA station.
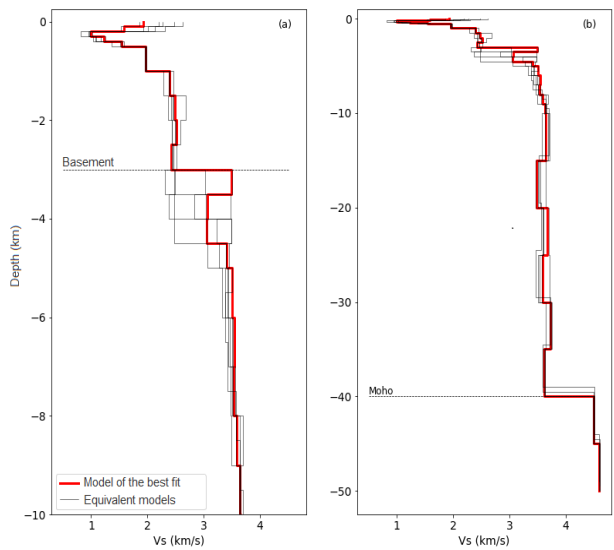

Fig. 9 - Final models of inversions for MECA station. The profile on the left (a) shows the first $10 \mathrm{~km}$, the profile on the right (b) shows the entire velocity model.

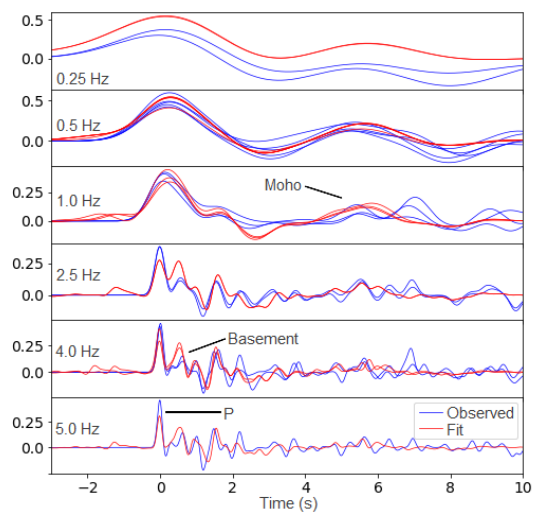

Fig. 10 - Inversion of receiver functions of frequencies 0.25 (top), 0.5, 1, 2.5, 4 and $5 \mathrm{~Hz}$ (bottom) of PSAL station.

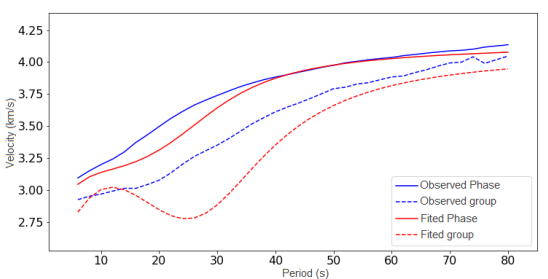

Fig. 11 - Inversion of dispersion curves of Rayleigh waves of PSAL station. 
Joint Inversion of Receiver Function and Dispersion Curves of Rayleigh Waves for determining of Layer Velocity Models in the Chaco-Paraná Basin

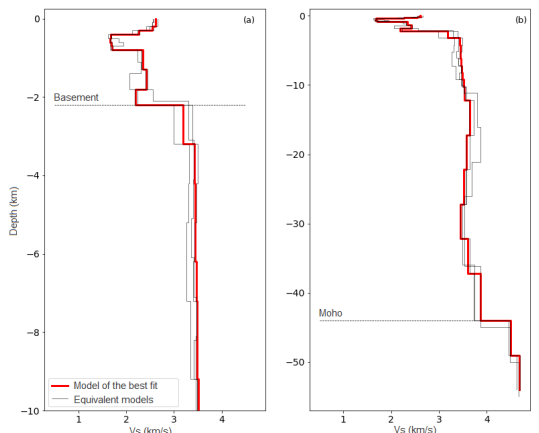

Fig. 12 - Final models of inversions for PSAL station. The profile on the left (a) shows the first $10 \mathrm{~km}$, the profile on the right (b) shows the entire velocity model.

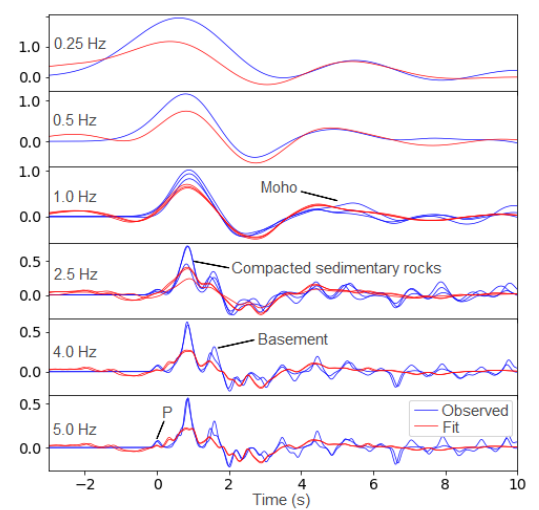

Fig. 13 - Inversion of receiver functions of frequencies 0.25 (top), 0.5, 1, 2.5, 4 and $5 \mathrm{~Hz}$ (bottom) of SCCA station.

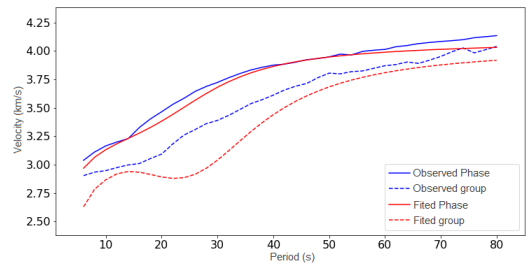

Fig. 14 - Inversion of dispersion curves of Rayleigh waves of SCCA station.

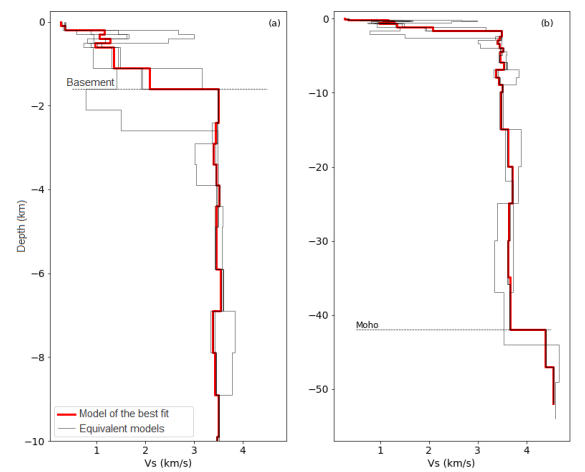

Fig. 15 - Final models of inversions for SCCA station. The profile on the left (a) shows the first $10 \mathrm{~km}$, the profile on the right (b) shows the entire velocity model.

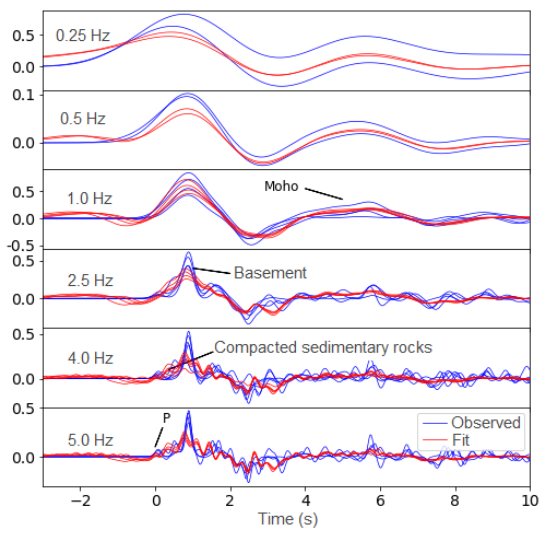

Fig. 16 - Inversion of receiver functions of frequencies 0.25 (top), $0.5,1,2.5,4$ and $5 \mathrm{~Hz}$ (bottom) of TICA station.

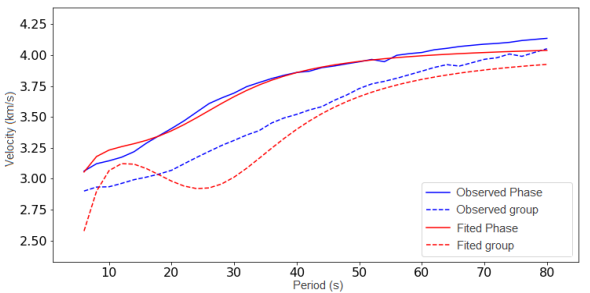

Fig. 17 - Inversion of dispersion curves of Rayleigh waves of TICA station.

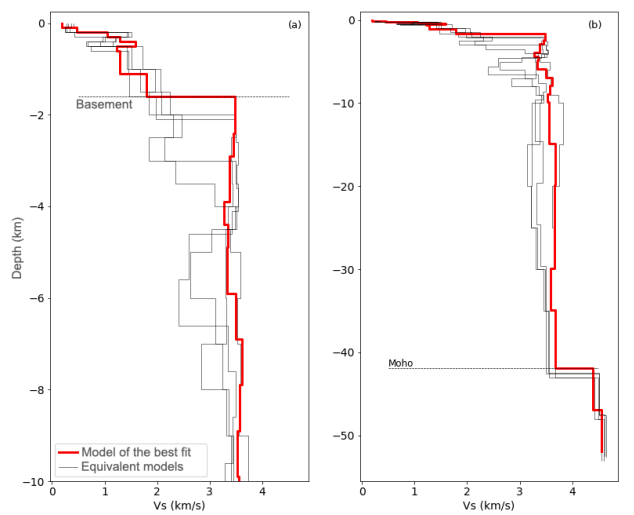

Fig. 18 - Final models of inversions for TICA station. The profile on the left (a) shows the first $10 \mathrm{~km}$, the profile on the right (b) shows the entire velocity model. 


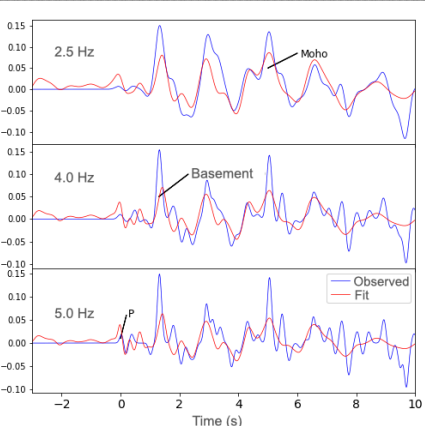

Fig. 19 - Inversion of receiver functions of frequencies 0.25 (top), 0.5, 1, 2.5, 4 and $5 \mathrm{~Hz}$ (bottom) of VACA station.

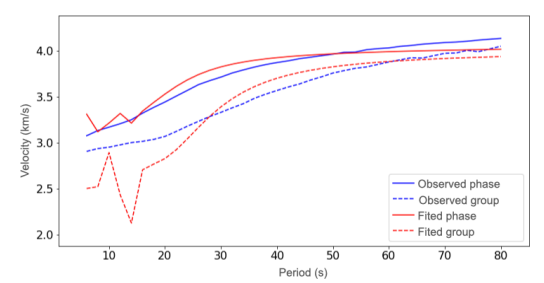

Fig. 20 - Inversion of dispersion curves of Rayleigh waves of VACA station.

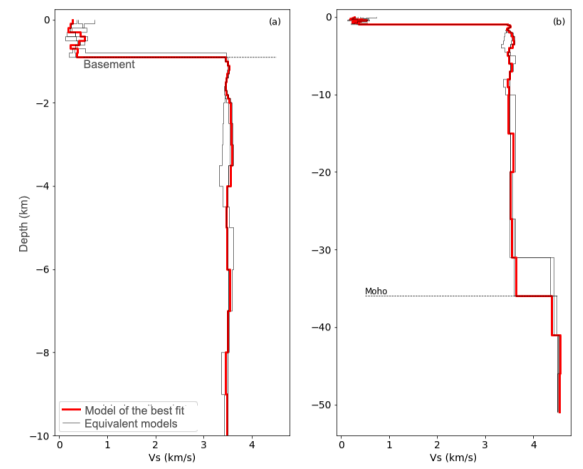

Fig. 21 - Final models of inversions for VACA station. The profile on the left (a) shows the first $10 \mathrm{~km}$, the profile on the right (b) shows the entire velocity model.

In general, the results indicate that the inversions were more stable at deep layers, whereas layers until $5 \mathrm{~km}$ deep had greater uncertainty in S-wave velocity. The Moho interface was well restricted and its greater uncertainty was for VACA station $(5 \mathrm{~km})$. This station had a noiser data due to its installation on soft sediments and we had difficulty getting good RF from it. Indeed, we were not able to use low frequency $(<2.5 \mathrm{~Hz})$ RF for this station, which explains the higher uncertainty for deep layers.

The greatest uncertainty for the basement was $2.5 \mathrm{~km}$ for ITQB station. It is known that this station was installed on a basalt outcrop and the final model had a high velocity layer $(\sim 3 \mathrm{~km} / \mathrm{s})$ at about $500 \mathrm{~m}$, coherent with the basalt. The basement is estimated at about $2.5 \mathrm{~km}$, which is consistent with results of Assumpção et al. (2009), who used a few drill holes to estimate the basement depth near 2 $\mathrm{km}$, but this value may be extrapolated because of the poor amount of data.
Fig. 22 and Tables 1 and 2 show the results for the basement and Moho depths in comparison with RivadeneyraVera et al. (2019) and Cedraz (2019) results. Our results show a mean depth of $2 \mathrm{~km}$ for the basement. Cedraz (2019) found the basement at $2.5 \mathrm{~km}$, but with low resolution due to the thick layers used in her models. Rosa et al. (2016) found the basement at $5 \mathrm{~km}$, but with dispersion curves with long periods, which are not appropriate for such shallow layers.

Table 1 - Moho depth in comparison with RivadeneyraVera et al. (2019) and Cedraz (2019) results.

\begin{tabular}{lccc}
\hline Station & This work $(\mathbf{k m})$ & Rivadeneyra-Vera et al. (2019) $(\mathbf{k m})$ & Cedraz (2019) $(\mathbf{k m})$ \\
\hline ITQB & 38.0 & 41.5 & 41.3 \\
PSAL & 44.0 & 45.4 & - \\
MECA & 40.0 & 40.4 & 38.4 \\
SCCA & 42.0 & 40.9 & - \\
VACA & 36.0 & 38.8 & - \\
TICA & 42.0 & 41.0 & - \\
\hline
\end{tabular}

Table 2 - Basement depth in comparison with Cedraz (2019) results.

\begin{tabular}{lcc}
\hline Station & This work $(\mathrm{km})$ & Cedraz $(2019)(\mathrm{km})$ \\
\hline ITQB & 2.5 & 2.5 \\
PSAL & 2.2 & - \\
MECA & 3.0 & 2.5 \\
SCCA & 1.6 & - \\
VACA & 0.9 & - \\
TICA & 1.6 & - \\
\hline
\end{tabular}

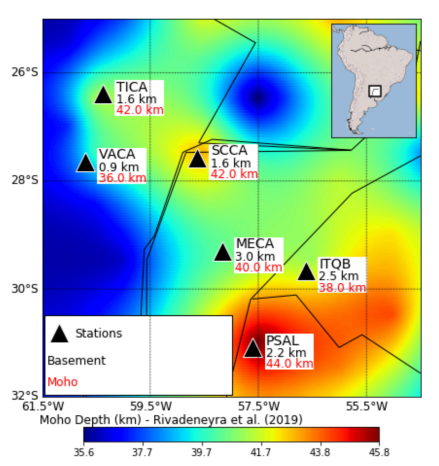

Fig. 22 - Basement and Moho depths in comparison with Rivadeneyra-Vera et al. (2019) results for Moho (color scale).

The greater uncertainty for the shallower layers and the bad fit of the shorter periods of dispersion may indicate that the range of periods in dispersion curves was not able to bring stability for the inversion at this depth. For the first $5 \mathrm{~km}$ of crust, shorter periods (from 2 to $4 \mathrm{~s}$ ) should be better for the joint inversion. But such short periods are not always possible to obtain because it depends on the stations distribution in the region. So, as an alternative, another data set could be added to the joint inversion, like the horizontal / vertical spectral ratio (Nakamura, 1989), which is sensitive to discontinuities in the wave velocities, like the basement interface. It should bring more stability to the inversion in the sedimentary layers. Also the group velocities of the observed dispersion curves are higher to the expected for the phase veloci- 
Joint Inversion of Receiver Function and Dispersion Curves of Rayleigh Waves for determining of Layer Velocity Models in the Chaco-Paraná Basin

ties. It may be due to the poor sampling of the region, which may have affected the dispersion curves and may have caused the bad fit of the inversion for the group velocities, especially for the short periods.

Despite the problems with the uncertainty of shallower layers, we can point to two distinct groups of sedimentary layers. The first group has very low S-wave velocity $(<1$ $\mathrm{km} / \mathrm{s}$ ) and may represent less compacted sedimentary cover of the Cenozoic. The second group has higher velocities (> $1.5 \mathrm{~km} / \mathrm{s}$ ) and may represent more compacted sedimentary rocks of the Paleozoic and the Mesozoic. The models present some low velocity layers that could be artifacts generated by the inversion due the great uncertainty.

\section{Conclusions}

Joint inversion of receiver functions and dispersion curves of Rayleigh waves in Chaco-Paraná Basin presented basement and Moho at mean depths of 2.0 and $40.3 \mathrm{~km}$, respectively. These values agree with recents results of Rivadeneyra-Vera et al. (2019) and Cedraz (2019), that pointed out that the crust is thicker than what was expected (Assumpção et al., 2013).

The basement was determined shallower than previous works (e.g. Rosa et al., 2016), but with more resolution. But it is still necessary to improve the uncertainty estimates, given that the periods used in dispersion curves were not short enough to bring stability for the inversion at this depth. A third data set could be added for the joint inversion, like $\mathrm{H} / \mathrm{V}$ spectral ratio, that is sensible to the velocity contrast of the basement interface.

We associated two features in the models to geological structures: first, a low velocity layer associated with less compacted sedimentary cover of the Cenozoic; second, a higher velocity layer, associated with more compacted sedimentary layers of the Paleozoic and Mesozoic.

\section{Acknowledgments}

Scholarship from CNPq - Brazil (144524/2018-0).

Scholarship from SBGf - Brazil (2018 and 2019).

\section{References}

Ammon, C., Randall, G. \& Zandt, G-. (1990). On the nonuniqueness of receiver function inversions. J. Geophys. Res., 95, 15303-15318.

Ammon, C. J. (1991). The isolation of receiver effects from teleseismic $P$ waveforms. Bull. of the Seism. Society of America, 81(6): 2504-2510.

Assumpção, M. S.; Barbosa, J. R.; Prado, R. L.; Bordotti, F.; Dias, F. (2009). Sedimentary Thickness in the Paraná Basin using High-Frequency Receiver Function: Estimated Depth of a Buried Graben in the MS/GO border. 11th International Congress of the Brazilian Geophysical Society, Salvador, BA.
Assumpção, M. S., Feng, M., Tassara, A., \& Julià, J. (2013). Models of crustal thickness of South America from seismic refraction, receiver functions and surface wave tomography. Tectonophysics, 609, 82-96.

Cedraz, V. M. A. S. (2019). Inversão simultânea de função do receptor e dispersão de ondas de superfície na Bacia do Pantanal (Dissertação de mestrado). Centro de Ciências Exatas e da Terra, Universidade Federal do Rio Grande do Norte.

Chulick, G. S., Detweiler, S. \& Mooney, W. D. (2013). Seismic structure of the crust and uppermost mantle of South America and surrounding ocean basins. Journal of South American Earth Sciences, 42, 260-276.

Feng, M., van der Lee, S., \& Assumpção, M. S. (2007). Upper mantle structure of South America from joint inversion of waveforms and fundamental mode group velocities of Rayleigh waves. Journal of Geophysical Research, 112, B04312.

Julià, J.; Ammon, C. J.; Herrmann, R. B.; Correig, A. M. (2000). Joint inversion of receiver function and surface wave dispersion observations. Geophys. Journal International. 143: 99-112.

Ligorría, J. P.; Ammon, C. J. (1999). Iterative Deconvolution and Receiver-Function Estimation. Bulletin of the Seismological Society of America, 89(5): 1395-1400.

Lloyd, S., van der Lee, S., França, G. S. Assumpção, M. S., \& Feng, M. (2010). Moho map of South America from receiver functions and surface waves. Journal of Geophysical Research, 115, B1115.

Milani, E. J., Thomaz Filho, A. (2000). Sedimentary Basins of South America. Tectonic Evolution of South America, 31, 389-449.

Nakamura, Y. (1989) A method for dynamic characteristics estimation of subsurface using microtremor on the ground surface, Quarterly Report of RTRI, 30(1), 25-33.

Owens, T. J.; Zandt, G.; Taylor, S. R. (1984). Seismic evidence for an ancient rift beneath the Cumberland Plateau, Tennessee: A detailed analysis of broadband teleseismic p waveforms. Journal of Geophysical Research, 89(B9): 7783-7796.

Rivadeneyra-Vera, J. C.; Bianchi, M. B.; Assumpção, M. S.; Cedraz, V. M. A. S.; Julià, J.; et al. (2019). An Updated Crustal Thickness Map of Central South America Based on Receiver Function Measurements in the Region of the Chaco, Pantanal and Paraná Basins, Southwestern Brazil. Journal of Geophysical Research: Solid Earth, 124: 8491-8505.

Rosa, M. L., Collaço, B., Assumpção, M. S., Sabbione, N., \& Sánchez, G. (2016). Thin crust beneath the ChacoParaná Basin by surface-wave tomography. Journal of South American Earth Sciences, 66, 1-14.

Shirzad, T.; Assumpção, M. S.; Bianchi, M. B. (2020). Ambient seismic noise tomography in West-Central and Southern Brazil: Characterizing the crustal structure of the Chaco-Paraná, Pantanal and Paraná Basins. Geophysical International Journal, 220 (3), 2074-2085. 